\title{
Gene expression profiles in human peripheral blood mononuclear cells as biomarkers for nutritional in vitro and in vivo investigations
}

\author{
Thomas Hofmann • Stefanie Klenow $\cdot$ \\ Anke Borowicki • Chris I. R. Gill • \\ Beatrice L. Pool-Zobel • Michael Glei
}

Received: 14 August 2009/ Accepted: 18 January 2010/Published online: 9 February 2010

(C) Springer-Verlag 2010

\begin{abstract}
Identification of chemopreventive substances may be achieved by measuring biological endpoints in human cells in vitro. Since generally only tumour cells are available for such investigations, our aim was to test the applicability of peripheral blood mononuclear cells (PBMC) as an in vitro primary cell model since they mimic the human in vivo situation and are relatively easily available. Cell culture conditions were refined, and the basal variation of gene expression related to drug metabolism and stress response was determined. Results were compared with profiles of an established human colon cell line (HT29) as standard. For biomarker development of nutritional effects, PBMC and HT29 cells were treated with potentially chemopreventive substances (chrysin and butyrate), and gene expression was determined. Key results were that relevant stress response genes, such as glutathione S-transferase T2 (GSTT2) and GSTM2, were modulated by butyrate in PBMC as in HT29 cells, but the blood cells were less sensitive and responded with high individual differences. We conclude that these cells may serve as a surrogate tissue in dietary investigations and the identified differentially expressed genes have the potential to become marker genes for population studies on biological effects.
\end{abstract}

T. Hofmann $(\bowtie) \cdot S$. Klenow · A. Borowicki ·

B. L. Pool-Zobel · M. Glei

Department of Nutritional Toxicology, Institute of Nutrition, Friedrich-Schiller-University Jena, Dornburger Str. 24, 07743 Jena, Germany

e-mail: th.hofmann@googlemail.com

C. I. R. Gill

Northern Ireland Centre for Diet and Health (NICHE), Centre for Molecular Biosciences (CMB),

Faculty of Life and Health Sciences, University of Ulster,

Coleraine BT52 1SA, Northern Ireland, UK
Keywords Biomarker - Butyrate - Gene expression · Human peripheral blood mononuclear cells · HT29 cells

$\begin{array}{ll}\text { Abbreviations } \\ C A T & \text { Catalase } \\ C O X-2 & \text { Cyclooxygenase-2 } \\ C V & \text { Coefficient of variation } \\ G S T M 2 & \text { Glutathione S-transferase } \mathrm{M} 2 \\ G S T P 1 & \text { Glutathione S-transferase P1 } \\ G S T T 2 & \text { Glutathione S-transferase T2 } \\ \mathrm{H}_{2} \mathrm{O}_{2} & \text { Hydrogen peroxide } \\ P B M C & \text { Peripheral blood mononuclear cells } \\ P H A & \text { Phytohemagglutinine } \\ \text { pPm } & \text { Parts per million } \\ S D & \text { Standard deviation } \\ \text { SOD2 } & \text { Superoxide dismutase 2, mitochondrial } \\ U G T 1 A 1 & \text { UDP glucuronosyltransferase 1 family, } \\ & \text { polypeptide A1 }\end{array}$

Introduction

A number of recent reports are showing that the latest technologies of genomics and proteomics have initiated a new era of biomarker development and many researchers are further developing the methods for cancer detection, treatment, and prevention [19, 46]. Different biomarker applications are based on blood cells such as PBMC, since they are obtained less invasively than biopsies and are suitable to measure systemic effects. Moreover, PBMC are used as surrogate tissues that may mimic effects occurring in remote target tissues of exposure [32, 37]. In vitro, these cells can be used as human primary cell models $[15,16]$. 
For this, PBMC are normally isolated from leucocyteenriched human blood preparations (buffy coats) and then treated with test substances over different periods before measuring distinct endpoints such as DNA damage. PBMC are suitable cells to analyse chemoprotective potentials of dietary food ingredients as has been shown in vivo after dietary interventions with fruit juices or water cress [14, 50]. In order to develop techniques for the evaluation of health effects in vitro further, it is necessary to assess the question how experimental conditions influence the selected parameters and how PBMC react to different stimuli in comparison to other target cells, such as a colon cancer cell line. For this approach, relevant genes related to stress response and drug metabolism were selected, namely GSTP1, GSTT2, GSTM2, UDP glucuronosyltransferase 1 family, polypeptide A1 (UGT1A1), catalase (CAT), superoxide dismutase 2 (SOD2), and cyclooxygenase-2 (COX-2). The protein products of these genes are linked to both oxidative stress and carcinogenesis. Expression levels of these genes have been shown to be altered in human cells by dietary compounds and metabolites such as butyrate and the flavonoid chrysin. Butyrate, formed by gut fermentation of dietary fibre [12, 33, 38], is believed to act as a potential chemopreventive agent [40]. Luminal concentration of butyrate in humans is found to range from 11 to $25 \mathrm{mM}$, and concentrations in human portal veins are 1,000-fold lower and further decrease in the venous serum [17]. Butyrate $(10 \mathrm{mM})$ treatment of primary colonocytes has been shown to modulate stress-related genes [38]. Gene expression of $C A T$ was induced, while $C O X-2$ was reduced in colon cancer cells through histone deacetylases inhibition [43]. In addition, incubation of human colon cells of different transformation state with butyrate induced GSTT2, GSTP1, and UGTIA1 [34]. Also, GSTM2 was strongly induced by $4 \mathrm{mM}$ butyrate in HT29 carcinoma cells [12]. PBMC were incubated with butyrate concentrations that reflect physiological concentrations for colonocytes but not for PBMC in order to test their suitability as surrogate tissue. Chrysin (5,7-dihydroxyflavone) is an inhibitor of the enzyme aromatase, which converts androgens to oestrogens, and a potent inducer of UGT1A1 catalytic activity in primary human hepatocytes, the human hepatoma cell line HepG2, and the human intestinal cell line CaCo-2 [13, 41].

In this study, we focused amongst others on phase II enzymes such as GSTs. These enzymes may be of importance in cancer development and therapy, and they can be modulated by dietary factors [20]. They catalyse nucleophilic attack by reduced glutathione (GSH) on nonpolar compounds that contain an electrophilic carbon, nitrogen, or sulphur atom [33]. The different isoenzymes show diverse substrate specificities and are influenced by both intrinsic (GST polymorphisms) and extrinsic factors (consumption of fruits and vegetables) [49].
The first aim of this study was to investigate the applicability of gene expression in PBMC as biomarker for in vivo and in vitro investigations. In particular, it was of practical importance to determine how cryopreservation and thawing of isolated PBMC affects survival, viability, and responsiveness to different treatments when measuring gene expression as biological endpoint. Normally, isolated human PBMC do not proliferate in cell culture. For this, phytohemagglutinine (PHA), a lectin extract from the kidney bean (Phaseolus vulgaris), is often used in vitro to stimulate the growth of PBMC [18, 36]. Here, we investigated how PHA, which may improve the suitability of PBMC as surrogate tissue by inducing proliferation, affects parameters of gene expression. The second objective consisted of investigating patterns of gene expression of important drug metabolism and stress response enzymes and their modulation by nutritional factors. To this end, we used cDNA array and real-time PCR technology in the cellular model that mimics the human in vivo situation (thus quiescent PBMC) and compared the results with an established cancer cell line (HT29). Knowledge about the effects and comparison of both cell types might aid in validating the potential of using gene expression profiles of PBMC as biomarkers for human in vivo as well as in vitro studies, which could also be used on a large scale, i.e. during clinical trials or intervention studies.

\section{Materials and methods}

\section{Test substances}

PHA (Roche Diagnostics, Mannheim, Germany) was diluted in Milli-Q water to obtain a stock solution of $5 \mathrm{mg} /$ $\mathrm{mL}$ and was further diluted in cell culture medium to yield a working solution of $10 \mu \mathrm{g} / \mathrm{mL}$. Butyrate (Merck KGaA, Darmstadt, Germany) was directly diluted in cell culture medium to reach the concentrations 4 and $10 \mathrm{mM}$. For chrysin (Sigma, Deisenhofen, Germany), a stock solution $(10 \mathrm{mM})$ in DMSO was prepared and further diluted in cell culture medium to reach a concentration of $10 \mu \mathrm{M}$. The final DMSO-concentration was $0.1 \%$.

\section{Cell culture of PBMC and HT29}

A fraction of mononuclear cells was isolated from several anonymous buffy coat preparations by gradient centrifugation using HISTOPAQUE ${ }^{\circledR}-1077$ (Sigma, Deisenhofen, Germany) as described earlier [6, 16]. All blood donors gave their informed consent. Cells were used either directly after isolation, kept in cell culture medium (PBMC medium: RPMI 1640 medium (Invitrogen $\mathrm{GmbH}$, Karlsruhe, Germany) with $10 \%$ heat-inactivated foetal calf serum, $1 \%$ 
penicillin/streptomycin (Invitrogen $\mathrm{GmbH}$, Karlsruhe, Germany), and 1\% L-glutamine (Invitrogen $\mathrm{GmbH}$, Karlsruhe, Germany)) overnight prior to incubation, or were cryopreserved at $-140^{\circ} \mathrm{C}$ (deep freezer QC 10140 , Nunc, Wiesbaden, Germany). These cells were thawed rapidly in a water bath at $37^{\circ} \mathrm{C}$ prior to each experiment.

For gene expression investigations over different time periods, a sample subset from a study by Gill et al. [14] was used. We analysed three time points, namely the start of the intervention, after an eight-week control phase, where the subjects were asked to maintain their habitual diet, and again after a seven-week washout phase, without any restrictions for the subjects. Collection of blood samples and isolation of PBMC were performed as previously described in the original study [14].

The human colon adenocarcinoma cell line HT29 is derived from a moderately differentiated, grade II adenocarcinoma of the rectosigmoid colon. These cells were obtained from the American Tissue Culture Collection (ATCC HTB-38) and maintained as a subconfluent monolayer culture in Dulbecco's Modified Eagle's Medium (DMEM; containing 4,500 mg/L glucose and $58 \mathrm{mg} / \mathrm{L}$ L-glutamine; Invitrogen $\mathrm{GmbH}$, Karlsruhe, Germany), supplemented with $10 \%$ foetal calf serum (Invitrogen $\mathrm{GmbH}$, Karlsruhe, Germany) at $37^{\circ} \mathrm{C}$ in a humidified incubator $\left(5 \% \mathrm{CO}_{2}, 95 \%\right.$ humidity). We used passages $23-$ 37 (after receipt from the ATCC) for the experiments reported in this paper.

\section{Treatment of PBMC and HT29 cells}

The number of PBMC was adjusted to $4 \times 10^{6}$ cells $/ \mathrm{mL}$, and cells were incubated with the test substances for $24 \mathrm{~h}$ in $25 \mathrm{~cm}^{2}$ cell culture flasks. Cell number and viability of PBMC were determined before and after treatment with the test substances using a trypan blue solution (SigmaAldrich Chemie GmbH, Taufkirchen, Germany) in a hemacytometer. HT29 cells were seeded in $25 \mathrm{~cm}^{2}$ cell culture flasks $\left(4 \times 10^{6}\right.$ cells $)$ and incubated $24 \mathrm{~h}$ later with the test substances for additional $24 \mathrm{~h}$. Cell number and viability were also determined using a trypan blue solution.

\section{Cytofluorometry}

The expression of CD3, CD4, CD8, CD14, CD19, CD20, CD28, and CD56 was measured in PBMC (isolated from different buffy coats) by FACSCalibur ${ }^{\circledR}$ using CellQuest Pro Software (BDBiosciences, Heidelberg, Germany) and standard procedures. Antibodies were labelled with fluorescein isothiocyanate (FITC) or phycoerythrin (PE) and were obtained from different sources (CD3 and CD14 (Immunotech, Marseille, France), CD4 and CD8 (Beckman Coulter, Marseille, France), CD19 (BDBiosciences,
Heidelberg, Germany), CD20 and CD28 (Serotec Düsseldorf, Germany), and CD56 (Biozol, Eching, Germany)).

RNA isolation

Total RNA from PBMC and HT29 cells was isolated from unfrozen cells using RNeasy Mini Kit (Qiagen, Hilden, Germany), dissolved in $50 \mu \mathrm{L}$ RNase free water and stored at $-20^{\circ} \mathrm{C}$. RNA quantification was done spectrophotometrically (Eppendorf BioPhotometer, Hamburg, Germany) or using a NanoDrop ND-1000 photometer (Thermo Fisher Scientific, Wilmington, United States) and either checked for integrity of the ribosomal RNA using formaldehyde denaturing RNA gel electrophoresis or Agilent Bioanalyzer 2100 and RNA 6000 Nano LabChip Kit (Agilent Technologies, Palo Alto, United States). The RNA Integrity Numbers (RINs) for the samples were obtained. Only RNA samples with RIN values of 7, or higher, were used for the analysis.

\section{Real-time PCR analysis}

Expression of mRNA was assessed by two-step SYBR Green I relative real-time PCR (iCycler iQ system, Bio$\mathrm{Rad} \mathrm{GmbH}$ München, Germany). Briefly, total RNA $(1 \mu \mathrm{g})$ was converted into first-strand cDNA using SuperScript ${ }^{\mathrm{TM}}$ First-Strand Synthesis System for RT-PCR (Invitrogen $\mathrm{GmbH}$, Karlsruhe, Germany) according to manufacturer's protocol. Using oligo(dT) leads to specific transcriptions of mRNA. The PCR amplification reactions contained $2 \mu \mathrm{L}$ of first-strand cDNA mixed with $12.5 \mu \mathrm{L}$ of iQ SYBR Green Supermix (Bio-Rad GmbH München, Germany, master mixture: $2 \times$ mix containing SYBR Green I dye, hot-start iTaq DNA polymerase, optimised buffer, and dNTPs qualified for quantitative PCR), 2.5 pmol of each of the specific primer pairs in a final reaction volume of $25 \mu \mathrm{L}$. All reactions were performed in duplicate. No-template controls $\left(2 \mu \mathrm{L} \quad \mathrm{H}_{2} 0\right)$ were included on each plate for each primer pair. The PCR profile consisted with initial denaturation of $2 \mathrm{~min}$ at $95^{\circ} \mathrm{C}, 40$ cycles of $30 \mathrm{~s}$ at $94^{\circ} \mathrm{C}$ denaturing, $30 \mathrm{~s}$ at $60^{\circ} \mathrm{C}$ annealing, $40 \mathrm{~s}$ at $72^{\circ} \mathrm{C}$ extension, and followed by final extension step of $10 \mathrm{~min}$ at $72^{\circ} \mathrm{C}$. Cumulative fluorescence was measured at the end of the extension phase of each cycle. Product-specific amplification was confirmed by melting curve analysis. Gene-specific primer sequences used for the quantification can be seen in Table 1. Confirmation of the gene specificity of primer nucleotides was performed using the NCBI-BLASTN search program and additionally after a test-PCR also with an agarose gel. Gene expression of all genes calculated based on the housekeeping gene GAPDH $\left(2^{\wedge}\left[-\mathrm{Ct}_{\text {target gene }}\right] / 2^{\wedge}\left[-\mathrm{Ct}_{G A P}\right.\right.$ $\left.{ }_{D H}\right]$ ) and expressed as parts per million (ppm). The main 
Table 1 Primer sequences (F forward, R reverse) for real-time PCR analysis

\begin{tabular}{|c|c|c|c|c|}
\hline Gene & Locus ID & & Primer sequences $5^{\prime}$ to $3^{\prime}$ & Product (bp) \\
\hline \multirow[t]{2}{*}{$C A T$} & \multirow[t]{2}{*}{ MN_001752 } & $\mathrm{F}$ & $5^{\prime}$-TGG ACA AGT ACA ATG CTG AG-3' & \multirow[t]{2}{*}{144} \\
\hline & & $\mathrm{R}$ & 5'-TTA CAC GGA TGA ACG CTA AG-3' & \\
\hline \multirow[t]{2}{*}{$C O X-2$} & \multirow[t]{2}{*}{ MN_000963 } & $\mathrm{F}$ & 5'-TCC TCC TGT GCC TGA TGA TTG C-3' & \multirow[t]{2}{*}{170} \\
\hline & & $\mathrm{R}$ & 5'-ACT GAT GCG TGA AGT GCT GGG-3' & \\
\hline \multirow[t]{2}{*}{$G A P D H$} & \multirow[t]{2}{*}{ MN_002046 } & $\mathrm{F}$ & 5'-ACC CAC TCC TCC ACC TTT GAC-3' & \multirow[t]{2}{*}{110} \\
\hline & & $\mathrm{R}$ & 5'-TCC ACC ACC CTG TTG CTG TAG-3' & \\
\hline \multirow[t]{2}{*}{ GSTM2 } & \multirow[t]{2}{*}{ MN_000858 } & $\mathrm{F}$ & $5^{\prime}$-AGC CGT ATG CAG CTG GCC AAA C-3' & \multirow[t]{2}{*}{149} \\
\hline & & $\mathrm{R}$ & 5'-GGA CAA AGG TGA TCT TGT CCC CA-3' & \\
\hline \multirow[t]{2}{*}{ GSTP1 } & \multirow[t]{2}{*}{ MN_000852 } & $\mathrm{F}$ & 5'-CTG CGC ATG CTG CTG GCA GAT C-3' & \multirow[t]{2}{*}{149} \\
\hline & & $\mathrm{R}$ & 5'-TTG GAC TGG TAC AGG GTG AGG TC-3' & \\
\hline \multirow[t]{2}{*}{ GSTT2 } & \multirow[t]{2}{*}{ MN_000854 } & $\mathrm{F}$ & $5^{\prime}$-TGA CAC TGG CTG ATC TCA TGG CC- $3^{\prime}$ & \multirow[t]{2}{*}{142} \\
\hline & & $\mathrm{R}$ & 5'-GCC TCC TGG CAT AGC TCA GCA C-3' & \\
\hline \multirow[t]{2}{*}{ UGT1A1 } & \multirow[t]{2}{*}{ MN_000463 } & $\mathrm{F}$ & $5^{\prime}$-TCA TGC TGA CGG ACC CTT TC-3' & \multirow[t]{2}{*}{145} \\
\hline & & $\mathrm{R}$ & $5^{\prime}$-CTG GGC ACG TAG GAG AAT GG-3' & \\
\hline \multirow[t]{2}{*}{ SOD2 } & \multirow[t]{2}{*}{ MN_000636 } & $\mathrm{F}$ & 5'-GCC CTG GAA CCT CAC ATC AAC-3' & \multirow[t]{2}{*}{111} \\
\hline & & $\mathrm{R}$ & 5'-CAA CGC CTC CTG GTA CTT CTC-3' & \\
\hline
\end{tabular}

reason for the choice of $G A P D H$ as the reference gene is the fact that it is also spotted on our cDNA-arrays used in this study. For these arrays, the spot intensities of the target genes were also based on the signal intensities for $G A P D H$. Gene expression results were evaluated and presented in the ppm-format, which gives more information, compared to the fold change-format, particularly, when comparing basal gene expression in different cells and cells from different donors. An external control was used to analyse the effects of PHA on the expression of GAPDH.

\section{cDNA array}

Hybridisation was performed on 112 sites (blanks, negative reference spots, housekeeping genes, and 96 human genes related to drug metabolism) on two different cDNA gene macroarrays (Human Drug Metabolism Gene Array HS11 and Human Stress \& Toxicity Gene Array HS12, SuperArray Bioscience Corporation, Frederick, MD, United States), as we have described before [46] according to the manufacturer's protocol. Spot intensities of the target genes were based on the signal intensities for $G A P D H$. Only $G A P D H$ has been expressed with sufficient intensities in both cell lines and was reasonably stable in our experiments, when comparing different blood donors (data not shown).

\section{Polymorphisms}

Cryopreserved lymphocytes were used to isolate DNA with the QIAamp ${ }^{\circledR}$ DNA Mini Kit (QIAGEN, Hilden, Germany) as described in the manufacturer's manual. A polymerase chain reaction (PCR) method was used to detect the presence or absence of the GSTM1 and GSTT1 genes for every blood donor using original procedures [3, 28]. A fragment of the B-globin gene was co-amplified as internal positive control in the PCR.

\section{Statistics}

Data were expressed as mean with standard deviation (SD) or single data points. The Prism software version 4.01 (Graph Pad, San Diego, United States) was used for two-sided paired and unpaired $t$-tests, one-way ANOVA with Bonferroni's multiple comparison test with selected pairs, and also two-way ANOVA with Bonferroni posthoc tests. A $P$ value below 0.05 was assumed to be significant.

\section{Results}

Characterisation and suitable cell culture conditions for PBMC

The two main subpopulations in PBMC, isolated from different buffy coats with a mean viability of $90 \pm 9 \%$ $(n=6)$, were lymphocytes $(76 \%)$ and monocytes $(15 \%)$ (Table 2). The CD expression of the isolated blood cells is summarised in Table 2.

For first experiments, PBMC were divided into two groups. One was treated directly after isolation, and the other was first frozen for storage, thawed and then 
Table 2 FACS analysis and Cluster of Differentiation (CD) expression in PBMC isolated from different buffy coats $(n=3)$

\begin{tabular}{lcr}
\hline Cells & Mean $(\%)$ & SD \\
\hline Lymphocytes & 75.6 & 4.0 \\
CD3 & 71.0 & 1.8 \\
CD4 & 41.7 & 17.2 \\
CD8 & 33.1 & 14.9 \\
CD19 & 10.8 & 2.6 \\
CD20 & 8.7 & 0.4 \\
CD28 & 48.4 & 21.0 \\
CD56 & 21.8 & 17.3 \\
Monocytes & 15.4 & 4.5 \\
Granulocytes & 9.0 & 8.1 \\
\hline
\end{tabular}

processed in identical fashion. Viability detected with trypan blue exclusion was not different between the buffy coats. The recovery of the cells after thawing was only $66 \pm 15 \% \quad(P=0.002)$, but viability of the remaining cells was not reduced. Freshly isolated and thawed PBMC $\left(4 \times 10^{6}\right.$ cells $\left./ \mathrm{mL}\right)$ were treated for $24 \mathrm{~h}$ with medium and PHA $(10 \mu \mathrm{g} / \mathrm{mL})$, and Table 3 shows the effects on different biological parameters. There were significantly reduced numbers of thawed PBMC in comparison to fresh PBMC after the 24-h incubation period $(43 \pm 15 \%$ calculated to the respective fresh PBMC). Viability of cryopreserved PBMC was reduced significantly in comparison to fresh PBMC. Treatment with PHA significantly reduced GSTM2 and CAT gene expression in fresh and cryopreserved PBMC (Table 3). In continuative experiments, we tested the reliability of GAPDH as housekeeping gene in the target cells. Down-regulation of $C A T$ and GSTM2 was based on a significant up-regulation (4.5fold in fresh PBMC, 2.4-fold in cryopreserved cells) of GAPDH after PHA treatment $(n=3)$. So, this effect was also more pronounced in fresh PBMC than in cryopreserved PBMC.
Basal gene expression in PBMC and HT29 based on two different platforms

Basal gene expression of selected target genes of drug metabolism and stress response in PBMC were compared with HT29 cells using two platforms, namely cDNA array and real-time PCR (Fig. 1). HT29 cells were used as a standard to determine whether the variations are based on the individual blood donors or technical variations. Lower variation of gene expression data in PBMC using cDNA array (Fig. 1a) may reflect the lower sensitivity of this particular cDNA technique in comparison to real-time PCR for which high inter-individual differences were detectable (Fig. 1b). For UGTIA1, high inter-individual variations (coefficient of variation (CV) 243\%) were measured, for some donors, UGTIAl was hardly detectable. Beside this gene, all other genes were expressed in every blood donor. GSTP1 and CAT were expressed at comparable levels in both PBMC and HT29 cells. COX-2 was the only gene with distinctly higher expression levels in primary PBMC than in HT29 colon carcinoma cells. According to cDNA array, GSTM2 was not expressed in HT29 cells. Real-time PCR investigations also showed quite low mRNA amounts for GSTM2.

Changes in individual basal gene expression over time

For several genes, high variations in gene expression in PBMC could be detected (Fig. 1b). In order to test whether these variations are just snap-shots or if they are specific for individuals, we analysed basal gene expression profiles for ten subjects after three different time points, namely at a starting point (week zero), after eight weeks, and again after 15 weeks. The results for three genes (UGTIA1, $S O D 2$, and GSTP1) can be seen in Fig. 2. For all genes, subjects with a low expression of a certain gene retained this low expression, and people with a high expression showed a comparable high expression during the different time points.

Table 3 Effects of treatment for $24 \mathrm{~h}$ with PHA $(10 \mu \mathrm{g} / \mathrm{mL})$ on cell number, viability, and relative gene expression of GSTM2 and CAT (based on $G A P D H$ ) in freshly isolated PBMC and cryopreserved PBMC

\begin{tabular}{|c|c|c|c|c|c|c|c|c|c|}
\hline & & \multicolumn{8}{|c|}{ Relative gene expression } \\
\hline & & \multicolumn{2}{|c|}{ Cell number $\left(10^{6} / \mathrm{ml}\right)$} & \multicolumn{2}{|c|}{ Viability (\%) } & \multicolumn{2}{|c|}{ GSTM2 } & \multicolumn{2}{|l|}{ CAT } \\
\hline & & Mean & SD & Mean & SD & Mean & SD & Mean & SD \\
\hline \multirow[t]{2}{*}{ Fresh } & Medium control & $3.97 \mathrm{a}$ & 1.05 & $96 \mathrm{c}$ & 2 & $1.00 \mathrm{e}$ & 0.00 & $1.00 \mathrm{~g}$ & 0.00 \\
\hline & PHA & $3.56 b$ & 0.51 & $94 d$ & 4 & $0.44 \mathrm{e}$ & 0.09 & $0.18 \mathrm{~g}$ & 0.01 \\
\hline \multirow[t]{2}{*}{ Cryopreserved } & Medium control & $1.83 \mathrm{a}$ & 0.67 & $82 \mathrm{c}$ & 9 & $1.00 \mathrm{f}$ & 0.00 & $1.00 \mathrm{~h}$ & 0.00 \\
\hline & PHA & $1.26 \mathrm{~b}$ & 0.20 & $71 d$ & 3 & $0.41 \mathrm{f}$ & 0.19 & $0.24 \mathrm{~h}$ & 0.06 \\
\hline
\end{tabular}

Statistical analysis was performed with one-way ANOVA and Bonferroni's multiple comparison test with selected pairs, and differences between fresh and cryopreserved cells were tested with two-way ANOVA, same letters indicate significant differences, $n=3$ 
Fig. 1 Relative gene expression (based on expression of housekeeping gene GAPDH [ppm]) of target genes in untreated cells in two different platforms: a cDNA array, b Real-time PCR. Basal gene expression in PBMC (filled characters) was characterised by high individual variation, whereas HT29 cells (open characters) demonstrated low variability. Variation was detected more sensitive in realtime PCR experiments. GSTM2 was not detectable in HT29 cells using cDNA array
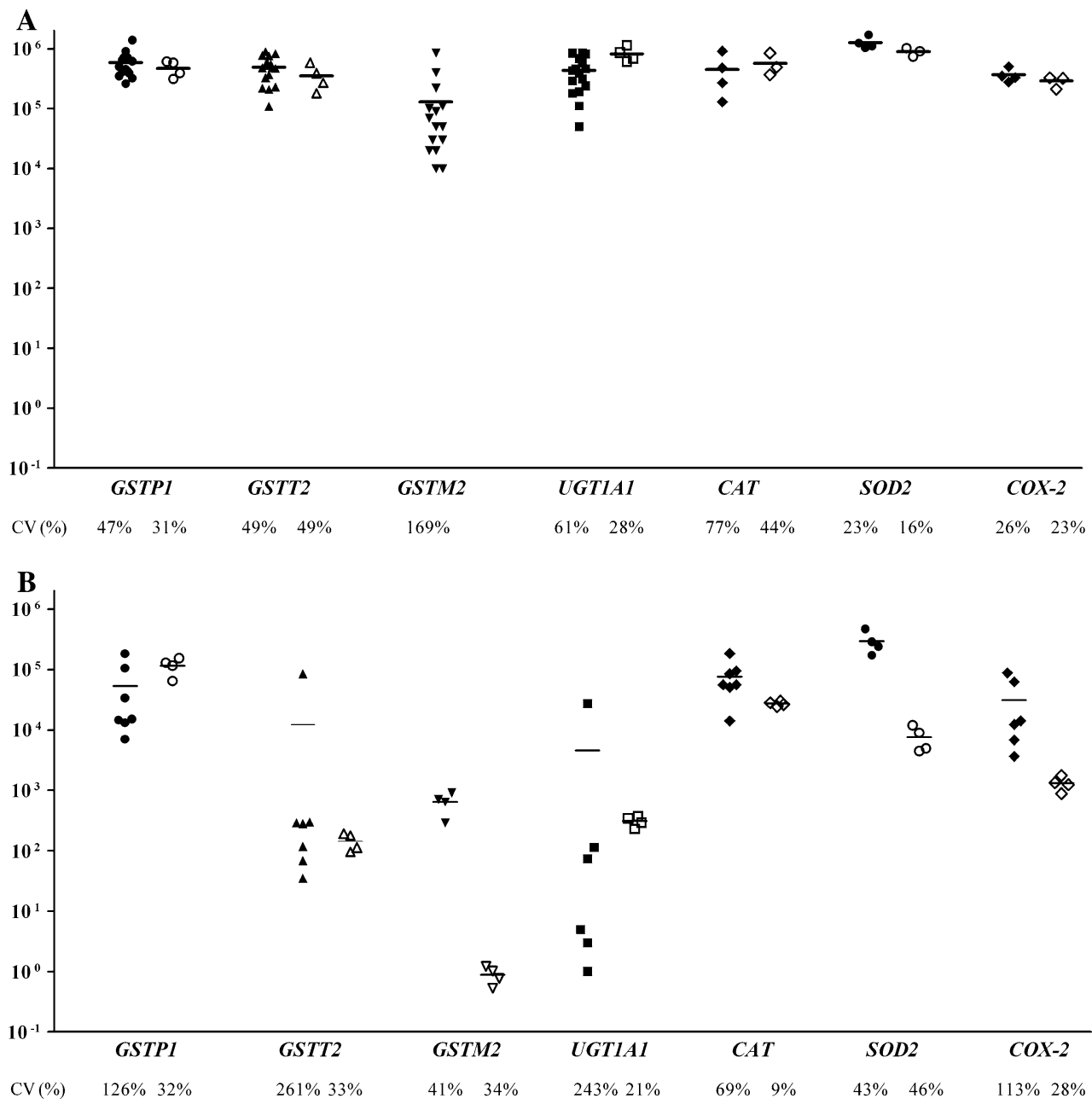

Modulation of gene expression in HT29 and PBMC after incubation with butyrate and chrysin

In analogy to previous studies [38], we incubated both cell types with either $4 \mathrm{mM}$ or $10 \mathrm{mM}$ butyrate. These concentrations are physiological for the colon cells [17] and are non-toxic for both cells types. For both concentrations, there was no significant influence on cell viability or on the cell amount detectable (data not shown). After $24 \mathrm{~h}$, relevant stress response genes such as GSTT2 and GSTM2 were significantly modulated in the same direction in HT29 cells and in PBMC (Fig. 3a, b). Butyrate (10 mM) significantly increased GSTT2 and GSTM2 gene expression in both cell types with much stronger effects on HT29. PBMC seemed to be less sensitive compared to colon cells and showed high variations from donor to donor. Chrysin, which is considered to be a potent UGT1Al inducer, showed a significant effect on GSTM2 expression, but no significant induction of UGT1A1, only a similar trend (fold change in PBMC 3.5, in HT29 1.5) could be detected in both cell types.
GSTM1 and T1 genotypes

Null polymorphisms (GSTM1*0 and GSTT1*0) of all blood donors $(n=8)$ used for the in vitro experiments were analysed to possibly explain individual responses. The frequencies of GSTM1 and GSTT1 null genotypes were 0.5 and 0.25 , respectively. One donor was negative for both enzymes $\left(G S T M 1 * 0\right.$ and $\left.G S T T 1^{*} 0\right)$. The stratification of subjects with different genotypes revealed no differences for in vitro experiments.

\section{Discussion}

The so-called surrogate tissue analysis is not a new concept, but using new DNA and RNA techniques could bring a multiplicity of important information and a better understanding of cellular pathways. Only a few studies in the recent years looked at gene expression profiles in human blood cells, with a focus on different diseases such 

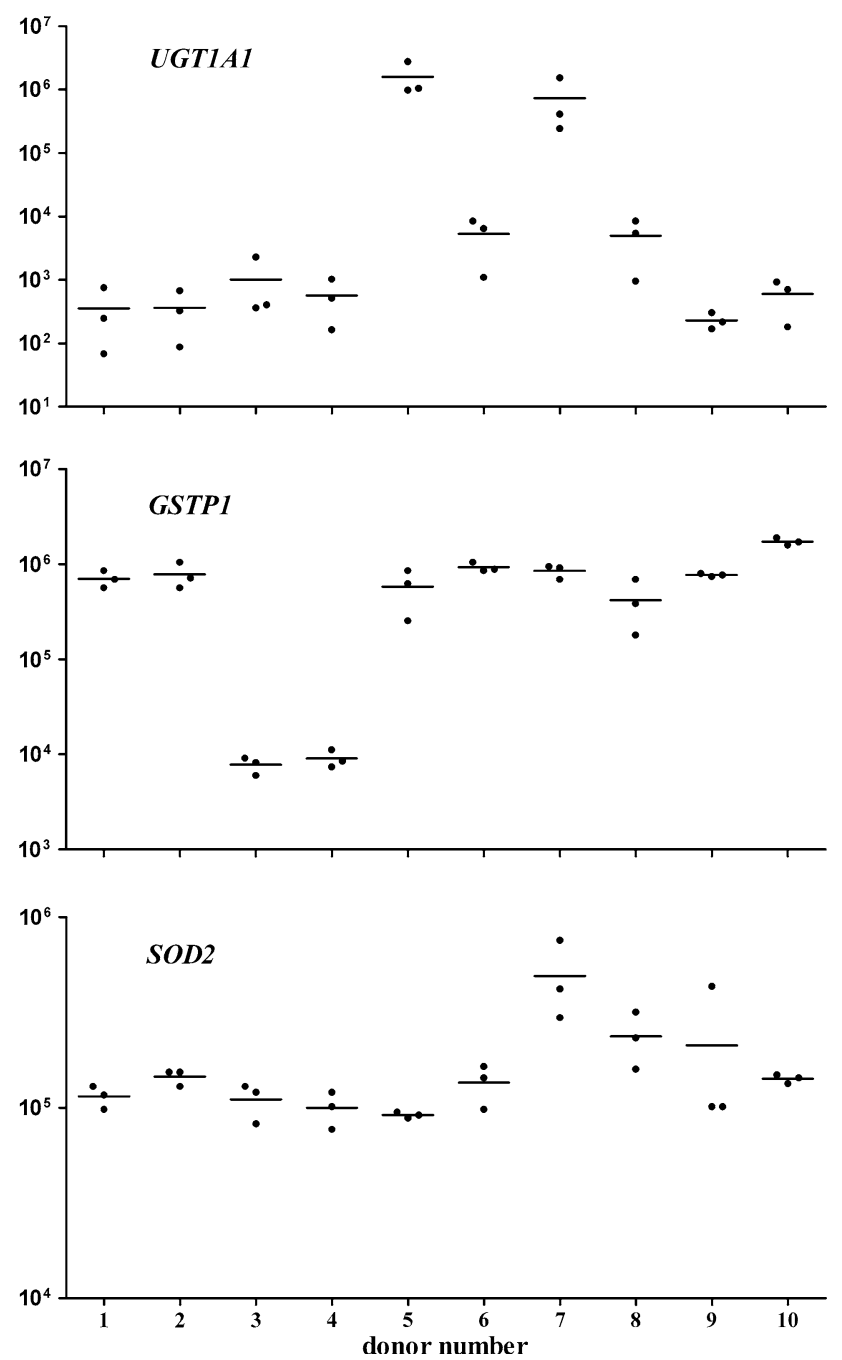

Fig. 2 Real-time PCR analysis of selected genes that were investigated in PBMC. Shown are the basal gene expression profiles for 10 subjects after three different time points, namely at a starting point (week zero), after 8 weeks, and again after 15 weeks. GAPDH (housekeeping gene) was used as internal reference control (gene expression related to $G A P D H$ [ppm])

as multiple sclerosis, cancer, or coronary heart disease $[1,7]$. Nutritional-related ex vivo transcriptomic modulations in human PBMC are not often investigated, with a few exceptions such as studies on $C O X-2$ modulation by quercetin [11] or the activation of the nuclear receptor peroxisome proliferator-activated receptor $\alpha(\operatorname{PPAR} \alpha)$ [4]. Our data help to define the extent and nature of the normal variability in gene expression in human blood cells and the feasibility of modulated gene expression in vitro. In this study, PMBC are used as a primary cell model as they are relatively easy to obtain, reflect individual differences and, importantly, give information for their potential use as target cells for further in vivo studies.

For practical reasons, PBMC obtained ex vivo are often cryopreserved until use. These cryopreserved PBMC are suitable and accepted biomarkers, e.g. to analyse effects of intrinsic and extrinsic factors on oxidative DNA damage $[30,39]$. Since modulation of gene expression was the endpoint in this study, we investigated how storage and the mitotic stimulation affect the responsiveness of these cells. The lectin PHA was included in this study since it is often used for detecting DNA damage or DNA repair in PBMC, because the ability of mammalian cells to remove DNA damage is correlated with cell activity [26, 48]. On the other hand, PHA possibly superposes effects of or interferes with the test substance. In our study, PHA significantly up-regulated the housekeeping gene $G A P D H$ by a factor of five after a 24-h incubation, a modulation which was also found by Vereninov et al. [47] in proliferating PBMC. Especially the regulation of housekeeping genes seems to be inappropriate for in vitro gene expression studies with PBMC. Significant induction of GAPDH by PHA was lower in cryopreserved PBMC, which indicates less responsiveness of cryopreserved PBMC to substances that modulate gene expression. Taken the results together, it seems to be advisable to use unfrozen and unstimulated PBMC for in vitro cell culture experiments.

We measured the expression of seven important drug metabolism and stress response genes simultaneously with two different platforms in PBMC and in the colon cancer cell line HT29. The measurement of basal expression in PBMC has been performed without any previous inductions. All investigated genes were expressed in each individual, with the exception of UGTIAl in one donor. Thus, these blood cells fulfil one important qualification to be considered as a suitable surrogate tissue, which may indicate the status of cellular detoxification systems in humans and the possible modulation by food ingredients. The differences between individual donors were higher compared to HT29 (Fig. 1). Since the colon cancer cells are derived from one clone and should have a stable gene expression, we used them as reference to make statements possible about the individual differences in PBMC. In the blood cells, particularly high variations could be detected for UGT1A1 (CV 243\%) and for GSTT2 (CV 261\%). For UGTIAl, these high variations may be caused by the numerous polymorphisms in the UGTIAl gene [10]. The most common polymorphism in Caucasian populations is a TA insertion in the TA(TA) ${ }_{6}$ TAA sequence in the promoter region, which is responsible for a decreased transcription rate [35]. The baseline gene expression level in PBMC could be also of particular importance for nutritional interventions. One hypothesis, which is supported by studies by Chow et al. [9] is that differential effects on activity of detoxifying enzymes are based on baseline enzyme level. In addition, it is interesting that basal gene expression seems to be quite conserved in individuals, since the expression levels of three investigated genes 
Fig. 3 a and b Real-time PCR analysis of selected genes that were investigated in PBMC (left side) and HT29 cells (right side). Shown are effects of butyrate and chrysin after 24-h incubation on the expression levels of $C A T$, SOD2, $C O X-2$, UGT1A1, GSTP1, GSTT2, and GSTM2. The modulations of mRNA levels were obtained by comparing the treatment groups to the medium controls and calculating the fold changes. GAPDH (housekeeping gene) was used as internal reference control (gene expression related to $G A P D H$ [ppm]). Significant differences to the controls were calculated by a one-way ANOVA with Bonferroni's post-test $(* * * P<0.001$, $* * P<0.01, * P<0.05$, $n=4-7$ for PBMC and $n=3-4$ for HT29)

A

PBMC

HT29
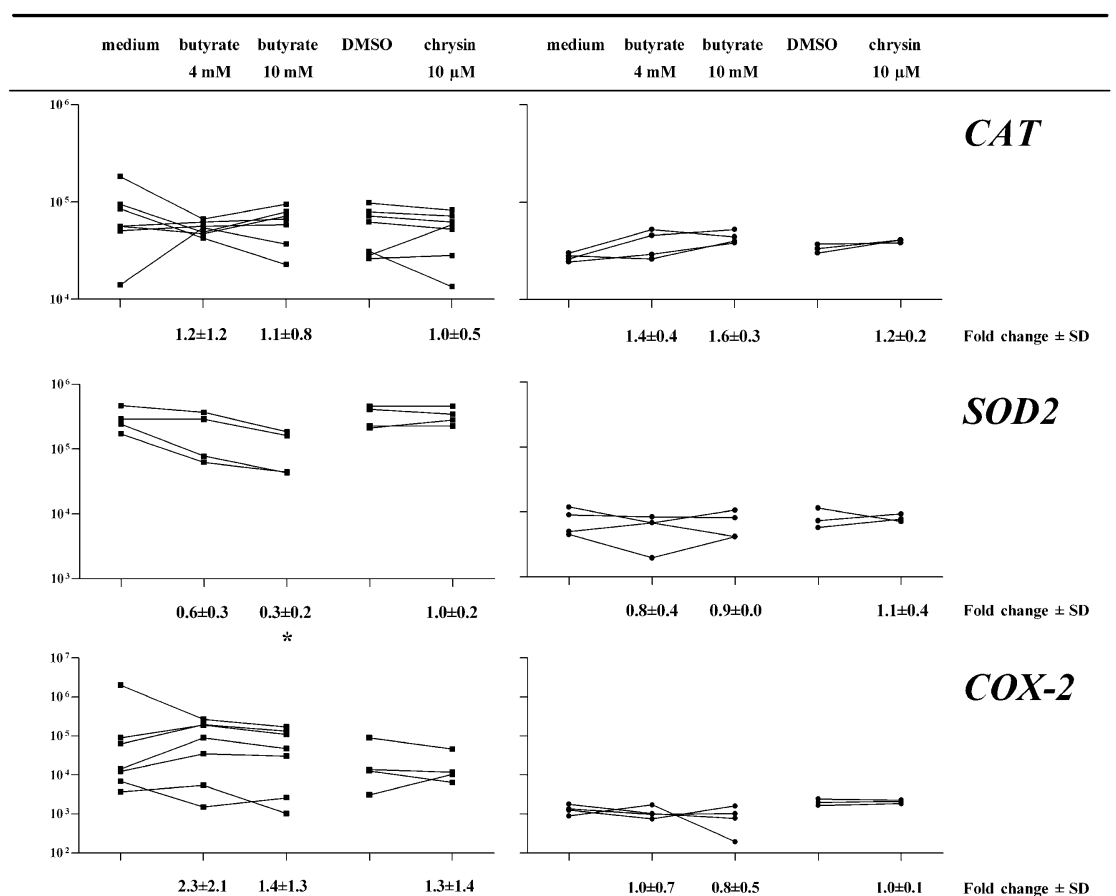

COX -2

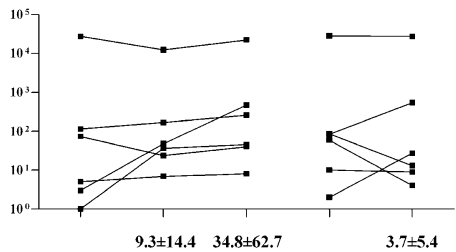

UGT1A1
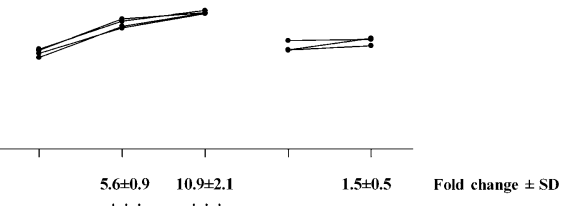

B

PBMC

HT29

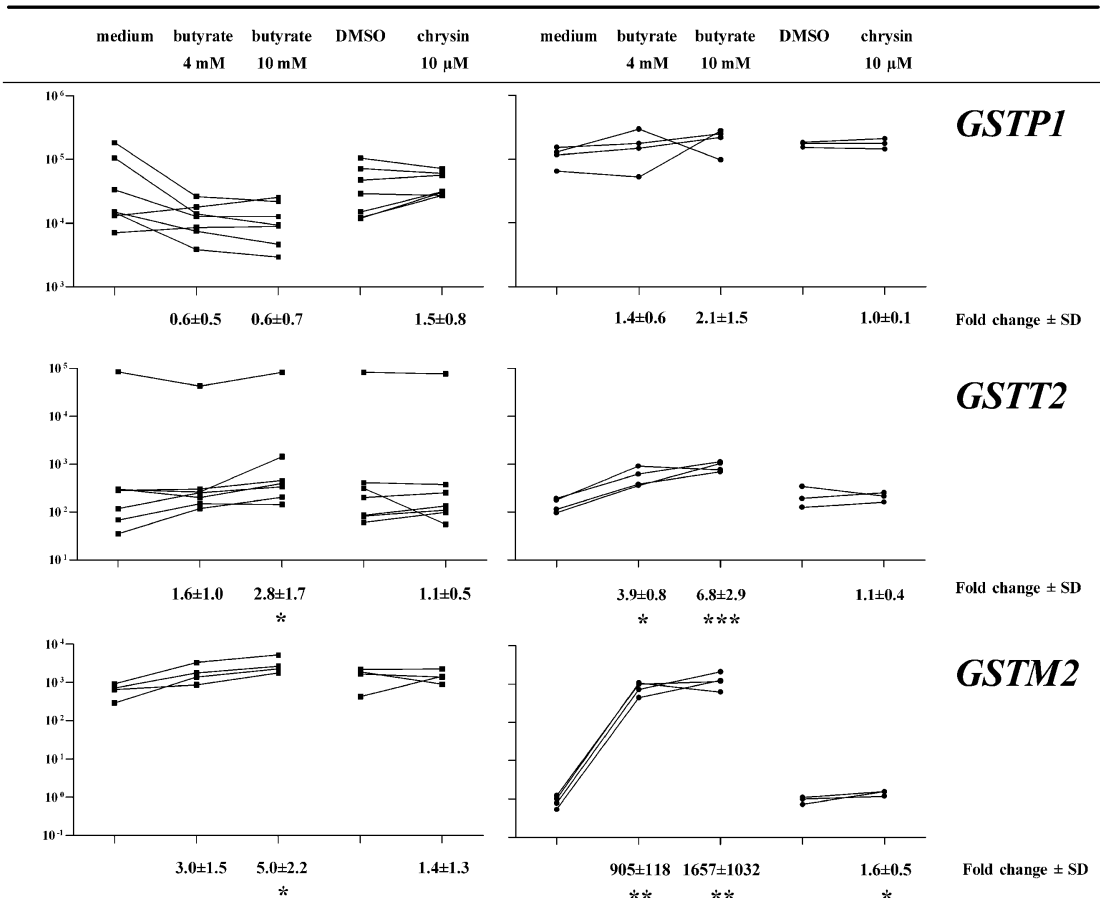


showed just minimal intra-individual but high inter-individual changes. Our data suggest the hypothesis that there are no individuals with a general low baseline detoxification capacity; rather every individual has a specific pattern for different detoxification enzymes.

Beside the basal expression of the investigated genes, another requirement for biomarker development is the responsiveness of cells to in vivo/in vitro stimuli. After incubation with $10 \mathrm{mM}$ butyrate, there was a significant up-regulation of GSTT2 and GSTM2 in both cell types. GSTM2 catalyses the detoxification of oxidised metabolites (o-quinones) of catecholamines and may serve as an antioxidant system preventing degenerative cellular processes [2]. The observation that GSTM2 mRNA was not detectable in untreated HT29 cells is in line with the observation of Ebert et al. [12] who could neither detect GSTM2 mRNA nor GSTM2 protein in unstimulated HT29 cells. GSTT2 has peroxidase activity towards t-butyl hydroperoxide and most pronounced against cumene hydroperoxide, whereas there is no detectable activity towards $\mathrm{H}_{2} \mathrm{O}_{2}$ [21, 24, 42]. GSTT2 polymorphisms are associated with colorectal cancer risk [25], and GSTT2 protein levels can be enhanced in rat colon by administration of acetyl salicylic acid, which has been shown to reduce rat colon cancer risk [45]. Therefore, the enhanced levels of GSTT2 and GSTM2 products possibly result in an elevated detoxification of peroxides or other oxidised metabolites. This suggests a better protection of butyratetreated cells during situations of metabolic and oxidative stress. It remains to be elucidated whether the typical expression patterns may afford chemoresistance of the cells to appropriate substrates, some of which may be cancer risk factors. On one hand, an induction of GSTs in primary cells seems straightforward and favourable since this should result in an enhanced detoxification of risk factors. In tumour cells such as HT29 on the other hand, GST induction could counteract cancer chemotherapy by causing resistance to therapeutic agents, thereby enhancing the survival of transformed cells. GSTP1 is one of the main extrahepatic GSTs and is markedly expressed in PBMC, where it may serve as a biomarker for induction of phase II enzymes by dietary intervention [31]. The decrease in GSTP1 gene expression in PBMC is possibly specific for these cells, since other studies also reported a reduction in GSTP1 on mRNA and protein level after fruit or vegetable consumption [22, 29].

To our knowledge, this is the first study on PBMC, which shows that phase II enzymes can be modulated in unstimulated cells by food metabolites such as butyrate in vitro. This indicates that PBMC react in vitro to physiological stimuli, which is a necessary prerequisite for the development of gene expression as a suitable biomarker. One important question for the future is the involved mechanism that is critical for regulation of theses enzymes. Some GSTs show an antioxidant/electrophile-responsive element (ARE/ERE) with the nuclear factor E2-related factor 2 (Nrf2) that can act on the ARE element and Nrf2 is important for the expression of many GSTs [8]. Thimmulappa et al. could show an Nrf2-dependent induction of antioxidative genes in PBMC by triterpenoids. Whether Nrf2 and/or ARE are important for the induction of GSTs by butyrate in PBMC is not known and is an important question for further studies.

In humans, the glucuronidation of small lipophilic agents is catalysed by the UGTs in the endoplasmic reticulum. This metabolic pathway leads to the formation of water-soluble metabolites originating from normal dietary processes, cellular catabolism, or exposure to drugs and xenobiotics. A polymorphism in the promoter region of the UGT1Al gene with seven instead of six thymine adenine (TA) repeats is responsible for the activity of this enzyme [35]. In a study by $\mathrm{Hu}$ et al., a greater than 200-fold interindividual variability was observed in both the glucuronidation and covalent binding of toxic metabolites in human PBMC [23]. Similar to these huge differences, we could also detect enormous variations in the modulation of gene expression after incubation with butyrate. Four of six blood donors showed a strong induction of UGT1A1 in PBMC. In addition, the flavonoid chrysin, which is a potent UGT1A1 inducer in many colon cell lines and liver cells [13], had modulatory effects on gene expression in PBMC of just a few blood donors.

Gene expression analyses in PBMC reflected huge differences in inducability of selected enzymes by the different food factors, indicating a possible subject-specific nutrient response, a hypothesis which is also concluded by other authors [5]. The differences were quite obviously much higher compared to cell culture cells such as HT29. This could not be explained until now by analysis of different polymorphisms (e.g. GSTT1, GSTM1). The number of blood donors, which have to be investigated for in vivo experiments, should be higher than the number of cell culture experiments. In addition, it will be important to find out the reasons for the different modulation patterns in the individual blood donor.

In this study, PBMC were used as surrogate target cells for effects that may also occur in well-established cell culture models as well as in the target organs in vivo. Since nearly all investigated drug metabolism and biotransformation enzymes are expressed on mRNA-level in PBMC and some genes could be modulated by food ingredients, PBMC seem to be a suitable tool for in vitro and ex vivo gene expression investigations. This hypothesis is also supported by a study by van Baarsen et al. [44] that could show that responses of in vitro stimulated PBMC isolated prior to treatment are consistent with those of the ex vivo 
results. A critical question is whether these effects in PBMC at gene expression level are comparable to that in the target organs. Liew et al. [27] could show that approximately $80 \%$ of genes expressed in many tissues such as brain, liver, lung, or stomach were also found expressed in blood cells, which is a first criteria of being a successful surrogate tissue. Also, preliminary investigations from our group (data not shown) with cDNA-arrays showed that there is a significant correlation between gene expression of PBMC as surrogate and primary colonocytes as target tissue of the same donor (mean $\mathrm{r}_{\text {pearson }}=0.78$ ).

In summary, our study demonstrates that nutritional food ingredients modulate gene expression in human PBMC in vitro and that this ex/in vitro method is a suitable nutrigenomics biomarker approach. Furthermore, the identified differentially expressed genes could become marker genes for population studies on biological effects of an intervention in humans. One of the questions that need to be answered in the future is whether the genes involved in stress response and drug metabolism can be modulated by nutrition in vivo, if the modulation is associated with antigenotoxic effects and if the changes in the blood cells reflect changes that occur in the specific target tissue.

Acknowledgments We acknowledge Prof. Gertrud Maria Hänsch and Birgit Prior, Institute for Immunology, University Heidelberg, Germany, for analytical assistance.

Conflict of interest The authors report no conflicts of interest. The authors alone are responsible for the content and writing of the paper.

\section{References}

1. Achiron A, Gurevich M (2006) Peripheral blood gene expression signature mirrors central nervous system disease: the model of multiple sclerosis. Autoimmun Rev 5:517-522

2. Baez S, Segura-Aguilar J, Widersten M, Johansson AS, Mannervik B (1997) Glutathione transferases catalyse the detoxication of oxidized metabolites (o-quinones) of catecholamines and may serve as an antioxidant system preventing degenerative cellular processes. Biochem J 324(Pt 1):25-28

3. Bell DA, Taylor JA, Paulson DF, Robertson CN, Mohler JL, Lucier GW (1993) Genetic risk and carcinogen exposure: a common inherited defect of the carcinogen-metabolism gene glutathione S-transferase M1 (GSTM1) that increases susceptibility to bladder cancer. J Natl Cancer Inst 85:1159-1164

4. Bouwens M, Afman LA, Muller M (2007) Fasting induces changes in peripheral blood mononuclear cell gene expression profiles related to increases in fatty acid beta-oxidation: functional role of peroxisome proliferator activated receptor alpha in human peripheral blood mononuclear cells. Am J Clin Nutr 86:1515-1523

5. Bouwens M, Afman LA, Muller M (2008) Activation of peroxisome proliferator-activated receptor alpha in human peripheral blood mononuclear cells reveals an individual gene expression profile response. BMC Genomics 9:262
6. Boyum A (1968) Isolation of mononuclear cells and granulocytes from human blood. Scand J Clin Lab Invest 97:77-89

7. Burczynski ME, Twine NC, Dukart G, Marshall B, Hidalgo M, Stadler WM, Logan T, Dutcher J, Hudes G, Trepicchio WL, Strahs A, Immermann F, Slonim DK, Dorner AJ (2005) Transcriptional profiles in peripheral blood mononuclear cells prognostic of clinical outcomes in patients with advanced renal cell carcinoma. Clin Cancer Res 11:1181-1189

8. Chanas SA, Jiang Q, McMahon M, McWalter GK, McLellan LI, Elcombe CR, Henderson CJ, Wolf CR, Moffat GJ, Itoh K, Yamamoto M, Hayes JD (2002) Loss of the Nrf2 transcription factor causes a marked reduction in constitutive and inducible expression of the glutathione S-transferase GSTA1, GSTA2, GSTM1, GSTM2, GSTM3 and GSTM4 genes in the livers of male and female mice. Biochem J 365:405-416

9. Chow HH, Hakim IA, Vining DR, Crowell JA, Tome ME, Ranger-Moore J, Cordova CA, Mikhael DM, Briehl MM, Alberts DS (2007) Modulation of human glutathione s-transferases by polyphenone intervention. Cancer Epidemiol Biomarkers Prev 16:1662-1666

10. Costa E (2006) Hematologically important mutations: bilirubin UDP-glucuronosyltransferase gene mutations in Gilbert and Crigler-Najjar syndromes. Blood Cells Mol Dis 36:77-80

11. de Pascual-Teresa S, Johnston KL, DuPont MS, O'Leary KA, Needs PW, Morgan LM, Clifford MN, Bao Y, Williamson G (2004) Quercetin metabolites downregulate cyclooxygenase-2 transcription in human lymphocytes ex vivo but not in vivo. J Nutr 134:552-557

12. Ebert MN, Klinder A, Schäferhenrich A, Peters WHM, Sendt W, Scheele J, Pool-Zobel BL (2003) Expression of glutathione S-transferases (GST) in human colon cells and inducibility of GSTM2 by butyrate. Carcinogenesis 24:1637-1644

13. Galijatovic A, Otake Y, Walle UK, Walle T (2001) Induction of UDP-glucuronosyltransferase UGT1A1 by the flavonoid chrysin in Caco-2 cells-potential role in carcinogen bioinactivation. Pharm Res 18:374-379

14. Gill CI, Haldar S, Boyd LA, Bennett R, Whiteford J, Butler M, Pearson JR, Bradbury I, Rowland IR (2007) Watercress supplementation in diet reduces lymphocyte DNA damage and alters blood antioxidant status in healthy adults. Am J Clin Nutr 85:504-510

15. Glei M, Pool-Zobel BL (2005) The main catechin of green tea, (-)-epigallocatechin-3-gallate (EGCG), reduces bleomycin-induced DNA damage in human leucocytes. Toxicol In Vitro 20:295-300

16. Glei M, Liegibel UM, Ebert MN, Böhm V, Pool-Zobel BL (2002) $\beta$-Carotene reduces bleomycin-induced genetic damage in human lymphocytes. Toxicol Appl Pharmacol 179:65-73

17. Hamer HM, Jonkers D, Venema K, Vanhoutvin S, Troost FJ, Brummer RJ (2008) Review article: the role of butyrate on colonic function. Aliment Pharmacol Ther 27:104-119

18. Hammarstrom S, Hammarstrom ML, Sundblad G, Arnarp J, Lonngren J (1982) Mitogenic leukoagglutinin from Phaseolus vulgaris binds to a pentasaccharide unit in $\mathrm{N}$-acetyllactosaminetype glycoprotein glycans. Proc Natl Acad Sci USA 79:16111615

19. Han M, Liew CT, Zhang HW, Chao S, Zheng R, Yip KT, Song ZY, Li HM, Geng XP, Zhu LX, Lin JJ, Marshall KW, Liew CC (2008) Novel blood-based, five-gene biomarker set for the detection of colorectal cancer. Clin Cancer Res 14:455-460

20. Hayes JD, Flanagan JU, Jowsey IR (2005) Glutathione transferases. Annu Rev Pharmacol Toxicol 45:51-88

21. Hiratsuka A, Nishijima T, Okuda H, Ogura K, Watabe T (1997) Rat liver theta-class glutathione S-transferases T1-1 and T2-2: their chromatographic, electrophoretic, immunochemical, and functional properties. Anal Biochem 252:229-237 
22. Hofmann T, Liegibel U, Winterhalter P, Bub A, Rechkemmer G, Pool-Zobel BL (2006) Intervention with polyphenol-rich fruit juices results in an elevation of glutathione S-transferase P1 (hGSTP1) protein expression in human leucocytes of healthy volunteers. Mol Nutr Food Res 50:1191-1200

23. Hu Z, Wells PG (2004) Human interindividual variation in lymphocyte UDP-glucuronosyltransferases as a determinant of in vitro benzo[a]pyrene covalent binding and cytotoxicity. Toxicol Sci 78:32-40

24. Hussey AJ, Hayes JD (1992) Characterization of a human classTheta glutathione S-transferase with activity towards 1-menaphthyl sulphate. Biochem J 286(Pt 3):929-935

25. Jang SG, Kim IJ, Kang HC, Park HW, Ahn SA, Yoon HJ, Kim K, Shin HR, Lee JS, Park JG (2007) GSTT2 promoter polymorphisms and colorectal cancer risk. BMC Cancer 7:16

26. Kaminskas E, Li JC (1992) Repair of DNA damage induced by oxygen radicals in human non-proliferating and proliferating lymphocytes. Mutat Res 274:103-110

27. Liew CC, Ma J, Tang HC, Zheng R, Dempsey AA (2006) The peripheral blood transcriptome dynamically reflects system wide biology: a potential diagnostic tool. J Lab Clin Med 147:126-132

28. Pemble S, Schroeder KR, Spencer SR, Meyer DJ, Hallier E, Bolt HM, Ketterer B, Taylor JB (1994) Human glutathione S-transferase theta (GSTT1): cDNA cloning and the characterization of a genetic polymorphism. Biochem J 300:271-276

29. Persson I, He L, Fang C, Normen L, Rylander R (2000) Influence of vegetables on the expression of GSTP1 in humans-a pilot intervention study (Sweden). Cancer Causes Control 11:359-361

30. Piperakis SM, Visvardis EE, Sagnou M, Tassiou AM (1998) Effects of smoking and aging on oxidative DNA damage of human lymphocytes. Carcinogenesis 19:695-698

31. Pool-Zobel BL, Bub A, Liegibel UM, Treptow-van Lishaut S, Rechkemmer G (1998) Mechanisms by which vegetable consumption reduces genetic damage in humans. Canc Epid Biom Prev 7:891-899

32. Pool-Zobel BL, Dornacher I, Lambertz R, Knoll M, Seitz HK (2004) Genetic damage and repair in human rectal cells for biomonitoring: sex differences, effects of alcohol exposure, and susceptibilities in comparison to peripheral blood lymphocytes. Mutat Res 551:127-134

33. Pool-Zobel B, Veeriah S, Bohmer FD (2005) Modulation of xenobiotic metabolising enzymes by anticarcinogens-focus on glutathione S-transferases and their role as targets of dietary chemoprevention in colorectal carcinogenesis. Mutat Res 591:74-92

34. Pool-Zobel BL, Selvaraju V, Sauer J, Kautenburger T, Kiefer J, Richter KK, Soom M, Wolfl S (2005) Butyrate may enhance toxicological defence in primary, adenoma and tumor human colon cells by favourably modulating expression of glutathione $\mathrm{S}$-transferases genes, an approach in nutrigenomics. Carcinogenesis 26:1064-1076

35. Raijmakers MT, Jansen PL, Steegers EA, Peters WH (2000) Association of human liver bilirubin UDP-glucuronyltransferase activity with a polymorphism in the promoter region of the UGT1A1 gene. J Hepatol 33:348-351

36. Reed JC, Alpers JD, Nowell PC, Hoover RG (1986) Sequential expression of protooncogenes during lectin-stimulated mitogenesis of normal human lymphocytes. Proc Natl Acad Sci USA 83:3982-3986
37. Rockett JC, Burczynski ME, Fornace AJ, Herrmann PC, Krawetz SA, Dix DJ (2004) Surrogate tissue analysis: monitoring toxicant exposure and health status of inaccessible tissues through the analysis of accessible tissues and cells. Toxicol Appl Pharmacol 194:189-199

38. Sauer J, Richter KK, Pool-Zobel BL (2007) Physiological concentrations of butyrate favorably modulate genes of oxidative and metabolic stress in primary human colon cells. J Nutr Biochem 18:736-745

39. Schmezer P, Rajaee-Behbahani N, Risch A, Thiel S, Rittgen W, Drings P, Dienemann H, Kayser KW, Schulz V, Bartsch H (2001) Rapid screening assay for mutagen sensitivity and DNA repair capacity in human peripheral blood lymphocytes. Mutagenesis 16:25-30

40. Sengupta S, Muir JG, Gibson PR (2006) Does butyrate protect from colorectal cancer? J Gastroenterol Hepatol 21:209-218

41. Smith CM, Graham RA, Krol WL, Silver IS, Negishi M, Wang H, Lecluyse EL (2005) Differential UGT1A1 induction by chrysin in primary human hepatocytes and HepG2 cells. J Pharmacol Exp Ther 315:1256-1264

42. Tan KL, Board PG (1996) Purification and characterization of a recombinant human Theta-class glutathione transferase (GSTT22). Biochem J 315(Pt 3):727-732

43. Tong X, Yin L, Giardina C (2004) Butyrate suppresses Cox-2 activation in colon cancer cells through HDAC inhibition. Biochem Biophys Res Commun 317:463-471

44. van Baarsen LG, Vosslamber S, Tijssen M, Baggen JM, van d V, Killestein J, van der Pouw Kraan TC, Polman CH, Verweij CL (2008) Pharmacogenomics of interferon-beta therapy in multiple sclerosis: baseline IFN signature determines pharmacological differences between patients. PLoS ONE 3:e1927

45. Van Lieshout EM, Tiemessen DM, Roelofs HM, Peters WH (1998) Nonsteroidal anti-inflammatory drugs enhance glutathione S-transferase theta levels in rat colon. Biochim Biophys Acta 1381:305-311

46. Veeriah S, Miene C, Habermann N, Hofmann T, Klenow S, Sauer J, Bohmer F, Wolfl S, Pool-Zobel BL (2008) Apple polyphenols modulate expression of selected genes related to toxicological defence and stress response in human colon adenoma cells. Int $\mathrm{J}$ Cancer 122:2647-2655

47. Vereninov AA, Vassilieva IO, Yurinskaya VE, Matveev VV, Glushankova LN, Lang F, Matskevitch JA (2001) Differential transcription of ion transporters, NHE1, ATP1B1, NKCC1 in human peripheral blood lymphocytes activated to proliferation. Cell Physiol Biochem 11:19-26

48. Vollberg TM, Lee KA, Sirover MA (1984) Positive correlation between the extent of cell proliferation and the regulation of base excision repair. Cancer Res 44:2377-2381

49. Wark PA, Grubben MJ, Peters WH, Nagengast FM, Kampman E, Kok FJ, Van V (2004) Habitual consumption of fruits and vegetables: associations with human rectal glutathione S-transferase. Carcinogenesis 25:2135-2142

50. Weisel T, Baum M, Eisenbrand G, Dietrich H, Will F, Stockis JP, Kulling S, Rufer C, Johannes C, Janzowski C (2006) An anthocyanin/polyphenolic-rich fruit juice reduces oxidative DNA damage and increases glutathione level in healthy probands. Biotechnol J 1:388-397 